\title{
Novel Genipin-Cross-Linked Chitosan/Silk Fibroin Sponges for Cartilage Engineering Strategies
}

\author{
Simone S. Silva, ${ }^{,+, \ddagger}$ Antonella Motta, ${ }^{\S}$ Márcia T. Rodrigues, ${ }^{\dagger, \ddagger}$ Ana F. M. Pinheiro, ${ }^{\dagger, \ddagger}$ \\ Manuela E. Gomes, ${ }^{\dagger \neq}$ João F. Mano, ${ }^{\dagger, \ddagger}$ Rui L. Reis, ${ }^{\dagger, \ddagger}$ and Claudio Migliaresi ${ }^{\S}$ \\ 3B's Research Group-Biomaterials, Biodegradables, and Biomimetics, Department of Polymer \\ Engineering, University of Minho, Headquarters of the European Institute of Excellence on Tissue \\ Engineering and Regenerative Medicine, AvePark, Zona Industrial da Gandra, \\ 4806-909 Caldas das Taipas, Guimarães, Portugal, Institute for Biotechnology and Bioengineering (IBB), PT \\ Government Associated Laboratory, Braga, Portugal, and Department of Materials Engineering and Industrial \\ Technologies and INSTM Research Unit, via Mesiano 77, University of Trento, I-38050 Trento, Italy
}

Received May 15, 2008

\begin{abstract}
The positive interaction of materials with tissues is an important step in regenerative medicine strategies. Hydrogels that are obtained from polysaccharides and proteins are expected to mimic the natural cartilage environment and thus provide an optimum milleu for tissue growth and regeneration. In this work, novel hydrogels composed of blends of chitosan and Bombyx mori silk fibroin were cross-linked with genipin $(\mathrm{G})$ and were freeze dried to obtain chitosan/silk (CSG) sponges. CSG sponges possess stable and ordered structures because of protein conformational changes from $\alpha$-helix/random-coil to $\beta$-sheet structure, distinct surface morphologies, and $\mathrm{pH} /$

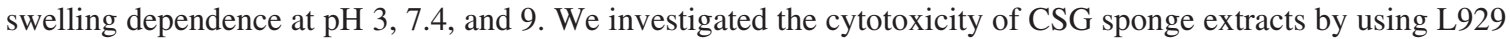
fibroblast-like cells. Furthermore, we cultured ATDC5 cells onto the sponges to evaluate the CSG sponges' potential in cartilage repair strategies. These novel sponges promoted adhesion, proliferation, and matrix production of chondrocyte-like cells. Sponges' intrinsic properties and biological results suggest that CSG sponges may be potential candidates for cartilage tissue engineering (TE) strategies.
\end{abstract}

\section{Introduction}

The development of materials that positively interact with tissues is an important step in the success of regenerative medicine strategies. Articular cartilage presents a specialized architecture that comprises chondrocytes embedded within an extracellular matrix (ECM) of collagen and proteoglycans ${ }^{1,2}$ and a limited repair capacity, which together with a high physical loading demand over this tissue make damaged cartilage exceedingly difficult to treat and heal. Different strategies have been developed to promote the repair or regeneration of cartilage tissue or osteochondral defects. ${ }^{1,3,4}$ Several in vivo studies stated the importance of cell-seeded biomaterials in treating cartilage lesions. ${ }^{5-7}$ The cell-carrier material should mimic the naturally occurring ECM because matrix components play a critical role in both in vitro and in vivo chondrogenesis. ${ }^{8}$ Porous matrices with adequate structural and mechanical properties such as hydrogels, sponges, and fibrous meshes have been widely used as 3D supports for cell adhesion, proliferation, and ECM formation. ${ }^{4,9}$ Natural-based porous matrices that are synthesized from biopolymers, namely, hyaluronic acid, ${ }^{10}$ collagen, ${ }^{11}$ chitosan,,${ }^{8,12}$ starch, ${ }^{13}$ and silk fibroin, ${ }^{14}$ have been proposed for cartilage tissue engineering (TE) because they represent a suitable and structural cellular environment. Chitosan (cht) and Bombyx mori silk fibroin (SF) are excellent natural raw materials for the design of porous matrices with potential advantages in terms of biocompatibility, chemistry versatility, and controlled degradability because of their intrinsic characteristics. ${ }^{8,14} \mathrm{Chi}-$

* To whom correspondence should be addressed. Tel: +351 253510900. Fax: +351 253510909. E-mail: simonesilva@dep.uminho.pt.

${ }^{\dagger}$ University of Minho.

Institute for Biotechnology and Bioengineering.

$\S$ University of Trento. tosan, a copolymer of D-glucosamine and $N$-acetylglucosamine groups that is derived from $\mathrm{N}$-deacetylation of chitin in arthropod exoskeletons, ${ }^{8}$ is well known for its susceptibility to chemical modification, its nontoxicity, and its enzymatic degradability. ${ }^{8,12}$ Chitosan is also structurally similar to various glycosaminoglycans (GAGs) that are present in articular cartilage, which makes it a promising candidate for cartilage TE applications. ${ }^{8}$ Conversely, SF, a fibrous protein that is derived from the silk Bombyx cocoon, is composed of 18 short sidechain amino acids that form antiparallel $\beta$ sheets in the spun fibers. ${ }^{14,15}$ Silk fibroin is considered to be a suitable material for skeletal TE because of its good oxygen and water-vapor permeabilities and its in vivo minimal inflammatory reaction. ${ }^{15-17}$ Notwithstanding, silk's exceptional biocompatibility as a cell culture on silk-based biomaterials has resulted in the formation of a variety of tissues including cartilage both in vitro and in vivo. $^{14}$

Cell-biopolymer interactions can be improved by the conjugation of different biopolymers and by bioactive agents (e.g., growth factors or RGD). ${ }^{18,19}$ Additionally, the possibility of conjugating the peculiar biocompatibility of SF with mechanical and biodegradation/biostability properties, which is typical of polymeric materials such as cht, is particularly attractive for the design of a tissue-engineered 3D scaffold. Therefore, we hypothesized that the cross-linking of cht/SF (CS) blended systems will favor the formation of stable matrices as 3D supports for chondrocyte proliferation and matrix production toward cartilage regeneration. The present work reports the first attempt to develop cross-linked hydrogels from CS blended systems with different CS ratios and by using genipin (G). Genipin, a natural cross-linking agent with lower cytotoxicity, ${ }^{20}$ is isolated from the fruits of the plant Gardenia jasminoides 

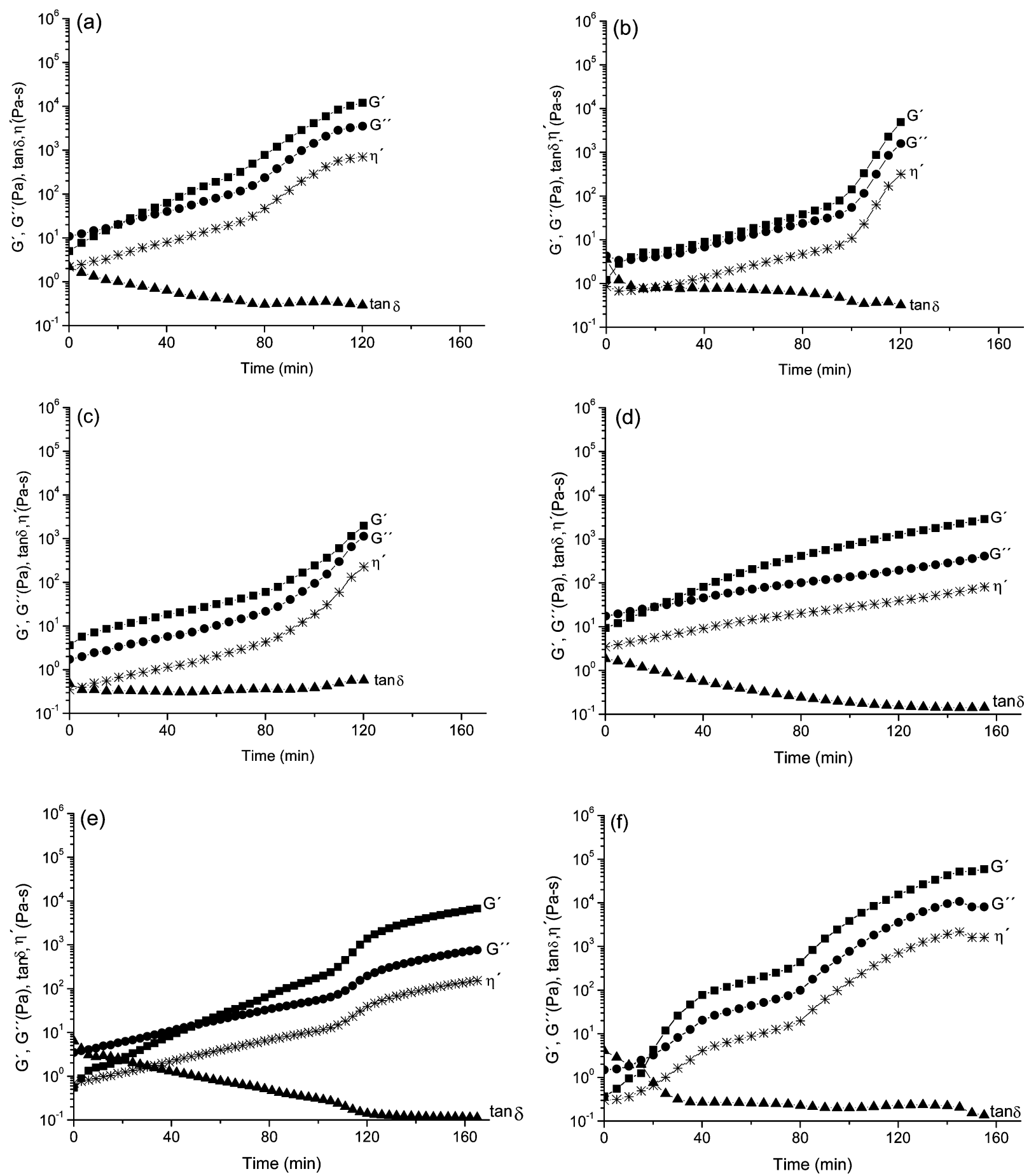

Figure 1. Time sweep profiles for non-cross-linked and cross-linked CS blended solutions (a) CS80, (b) CS50, (c) CS20, (d) CS80G, (e) CS50G, and (f) CS20G. Measurements were made at $\omega=5 \mathrm{rad} / \mathrm{s}$ at $37^{\circ} \mathrm{C}$. Symbols correspond to the storage modulus $G^{\prime}(\boldsymbol{\square})$, the loss modulus $G^{\prime \prime}$ $(\bullet)$, the dynamic viscosity $\eta^{\prime}(*)$, and $\tan \delta(\boldsymbol{\Delta})$. Data represent the mean \pm standard deviation $(n=3, p<0.05$, two-way ANOVA).

Ellis $^{20}$ and is obtained from geniposide, a component of traditional Chinese medicine. ${ }^{20}$ Genipin has been used to fix biological tissues ${ }^{8}$ and to cross-link amino-group-containing biomaterials such as $\mathrm{cht}^{21-23}$ and gelatin ${ }^{22,24}$ in different forms, such as microspheres, membranes, and nanofibers. However, to our knowledge, only a few approaches have involved genipin reactions with $\mathrm{SF}^{25,26}$ In our work, hydrogels that were produced by the cross-linking of CS systems were freeze dried to obtain the cross-linked cht/silk (CSG) sponges. We determined the cross-linking degree of the CSG sponges by using a ninhydrin assay. We studied the viscoelastic properties of the CS and CSG solutions, the structural changes, the morphological aspects, and the mechanical properties of the CSG sponges by using different techniques, namely, rheological measurements, Fourier transform infrared (FTIR) spectroscopy, environmental scanning electron microscopy (ESEM), micro-computed tomography (micro-CT), and dynamic mechanical analysis (DMA). To investigate a possible cytotoxicity effect of the developed materials, we placed CSG sponge extracts in contact with fibroblast-like cells (L929 cell line), and we conducted a cellular viability assay (MTS) for different culture time points. Furthermore, we also assessed the potential use of the developed materials in cartilage repair strategies by seeding and culturing ATDC5 chondrocyte-like cells onto the developed CSG sponges. 
Table 1. Effect of Reaction Time on the Physical Appearance of the Cross-Linked CS-Based Sponges during Reaction with Genipin at 37 ${ }^{\circ} \mathrm{C}$

reaction time $(h)$

\begin{tabular}{|c|c|c|c|c|c|}
\hline $\begin{array}{l}\text { blended } \\
\text { system }^{a}\end{array}$ & 0 & 1 & 3 & 5 & 24 \\
\hline CS80G & light yellow & gelled, blue green & gelled, dark blue & $\begin{array}{l}\text { fully gelled, } \\
\text { dark blue }\end{array}$ & $\begin{array}{l}\text { fully gelled, } \\
\text { dark blue }\end{array}$ \\
\hline CS20G & light yellow & viscous, blue green & $\begin{array}{l}\text { blue gel (top)/blue } \\
\text { green (bottom) }\end{array}$ & $\begin{array}{l}\text { dark-blue gel (top)/blue } \\
\text { green (bottom) }\end{array}$ & $\begin{array}{l}\text { fully gelled, } \\
\text { dark blue }\end{array}$ \\
\hline
\end{tabular}

${ }^{a}$ CS80G, CS50G, and CS20G correspond to 80/20, 50/50 and 20/80 wt \% CS cross-linked with genipin.

ATDC5 cells, which were previously described to follow the chondrogenic differentiation pathway, ${ }^{27}$ constitute an interesting and functional model system for primary chondrocytes in cell culturing methodologies. ATDC5 proliferation and morphology were assessed by the DNA quantification assay and SEM, respectively. To detect the formation of a cartilagelike ECM, we quantified GAGs in ATDC5-CSG sponge constructs.

\section{Experimental Section}

Materials. Reagent grade medium-molecular-weight cht (SigmaAldrich, CAS 9012-76-4) with a deacetylation degree of $84 \%$ determined by ${ }^{1} \mathrm{H} \mathrm{NMR}^{28}$ was used. Silk from cocoons of Bombyx mori was kindly provided by Cooperativa Socio Lario, Como, Italy. Genipin was a product of Wako Chemicals. All other chemicals were reagent grade and were used as received.

Preparation of Chitosan. We purified Cht by a reprecipitation method. ${ }^{29}$ Briefly, cht powder was dissolved at a concentration of $1 \%$ $(\mathrm{w} / \mathrm{v})$ in $2 \%(\mathrm{v} / \mathrm{v})$ aqueous acetic acid. The system was maintained under stirring overnight at room temperature (RT). After that, the solution was filtered twice to remove impurities. We then precipitated Cht by using $1 \mathrm{M}$ aqueous sodium hydroxide $(\mathrm{NaOH})$ while stirring the mixture. Finally, the cht was sufficiently washed with distilled water until it reached neutrality. White flakes of purified cht were obtained after lyophilization for 4 days.

Preparation of Silk Fibroin. Silk from cocoons of Bombyx mori was first degummed to remove sericins. We achieved the degumming process by boiling the silk filaments for $1 \mathrm{~h}$ in water that contained 1.1 $\mathrm{g} / \mathrm{L} \mathrm{Na} \mathrm{CO}_{3}$ (anhydrous), followed by $30 \mathrm{~min}$ in water with $0.4 \mathrm{~g} / \mathrm{L}$ $\mathrm{Na}_{2} \mathrm{CO}_{3}$. Finally, the resulting fibroin filaments were extensively rinsed in boiling distilled water and were air dried at RT. To prepare solutions to be used in the preparation of the materials, we dissolved fibroin in 9.3 M LiBr overnight at $65^{\circ} \mathrm{C}$. Then, the SF was dialysed in a SlideA-Lyzer cassette (Pierce, 3500 Da MWCO) against distilled water for 3 days at RT. The water was changed every $2 \mathrm{~h}$. After that, the cassettes were transferred to a new dialysis process in which the SF water solution was concentrated by dialysis against poly(ethylene glycol) (PEG) aqueous solution at a concentration of $25 \%(\mathrm{w} / \mathrm{v})$ for $2 \mathrm{~h}$. After dialysis, the final concentration of SF aqueous solution was determined by the use of a NanoDrop ND-1000 spectrophotometer (Delaware). The amino acid composition of SF was obtained by HPLC analysis.

Chitosan/Silk Fibroin Blended Solution Preparation, CrossLinking Reactions, and Sponge Formation. Cht powder was dissolved at a concentration of $5 \%(\mathrm{w} / \mathrm{v})$ in aqueous acetic acid $(3 \%, \mathrm{v} / \mathrm{v})$ overnight at RT. Silk fibroin was dissolved in water at a concentration of $7 \mathrm{wt} \%$. The two solutions were mixed in different ratios, namely, CS80, CS50, and CS20, which correspond to 80/20, 50/50, and 20/80 wt $\% \mathrm{CS}$, and were homogenized under constant agitation for $30 \mathrm{~min}$ at RT. Subsequently, genipin powder (12\% related to total weight of solute in solution) was added to the CS blended solutions under constant stirring for $5 \mathrm{~min}$ at RT. Then, the CS blended system was maintained under stirring for 5 and $24 \mathrm{~h}$ at $37{ }^{\circ} \mathrm{C}$. The resulting hydrogels were washed with distilled water. By this turn, sponges were obtained from hydrogels in a mold, were frozen at $-80{ }^{\circ} \mathrm{C}$ overnight, and were freeze dried for a period of 2 days to remove the solvent completely. CS sponges without genipin were used as control materials and were prepared according to the process described above. The identification of the cross-linked CS sponges was CSXGY, where X, G, and Y indicate the cht content in the blend, genipin, and the reaction time, respectively.

Characterization. Rheological measurements were carried out in an advanced rheometric expansion system (ARES, Shear Strain Controlled). The geometry was a stainless-steel plate/plate (2 $\mathrm{mm}$ diameter and $0.4 \mathrm{~mm}$ gap). The plate was equipped with a solvent trap to reduce evaporation during measurement. The measuring device was equipped with a temperature unit (Peltier plate) that provided a rapid change in the temperature and gave very good temperature control over an extended time. Dynamic rheological tests (time sweep) were used to characterize the behavior of the CS blended solutions and the build up of the network structure (hydrogel). Measurements were performed at $37{ }^{\circ} \mathrm{C}$, a frequency of $5 \mathrm{rad} / \mathrm{s}$, and $5 \%$ strain. Three solutions were used in each analysis. The gelling process was monitored for up to $3 \mathrm{~h}$. We used the measurements to determine the following parameters: elastic modulus $\left(G^{\prime}\right)$, viscous modulus $\left(G^{\prime \prime}\right)$, dynamic viscosity $\left(\eta^{\prime}\right)$, and phase angle $(\delta)$ as a function of time. The elastic modulus is a measure of the solidlike response of the material, whereas the viscous modulus is a measure of the liquidlike response of the material. The loss tangent $(\tan \delta)$, a parameter that represents the ratio between the viscous and elastic components of the modulus of the polymer, was also calculated $\left(\tan \delta=G^{\prime \prime} / G^{\prime}\right){ }^{30}$

The optical micrographs were recorded at RT in a Zeiss-Axiotech optical microscope (HAL 100, Germany).

We observed the morphology of the samples by using an ESEM (Philips XL 30, Philips, Eindhoven, The Netherlands) in low vacuum mode. We observed samples without any treatment at a vacuum pressure level of 0.8 Torr

We obtained the qualitative information about the porosity of the CSG sponge architectures by microtomography imaging by using a Skyscan 1072 X-ray microtomograph (Belgium). During the measurement, both the X-ray source and the detector were fixed while the sample rotated around a stable vertical axis. Samples were scanned at a voltage of $40 \mathrm{kV}$ and a current of $248 \mu \mathrm{A}$. After the reconstruction of the 2D cross sections, Skyscan CT-analyzer software was used to segment the images and determine their 3D porosity. We selected 200 slices of a region of interest that corresponding to the structure of sponges from the CT data set.

The infrared spectra of CS and CSG sponges were obtained with a Perkin-Elmer (Spectrum One FTIR) spectrometer in the spectral region of $4000-650 \mathrm{~cm}^{-1}$ with a resolution of $2 \mathrm{~cm}^{-1}$.

The cross-linking degree of each test group of samples was determined by the use of the ninhydrin assay. ${ }^{23,31}$ In the ninhydrin assay, ${ }^{23}$ the sample was first lyophilized for $24 \mathrm{~h}$ and was then weighed ( $3 \mathrm{mg}$ ). Subsequently, the lyophilized sample was heated with a ninhydrin solution $(2 \mathrm{wt} \% \mathrm{v} / \mathrm{v})$ at $100{ }^{\circ} \mathrm{C}$ for $20 \mathrm{~min}$. After the sample was heated with ninhydrin, the optical absorbance of the solution was recorded with a spectrophotometer (Bio-Rad SmartSpec 3000, CA) at 
(a)

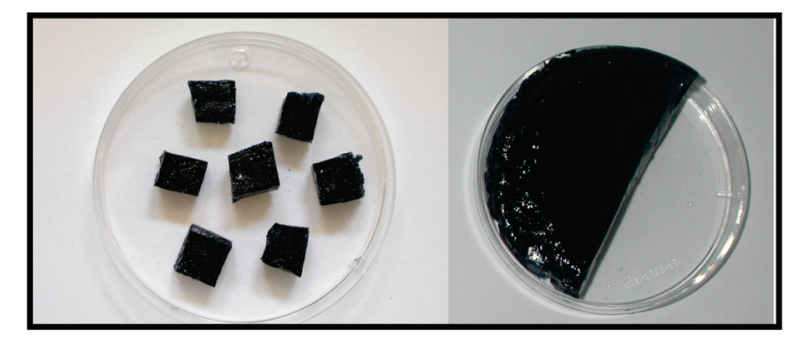

(b)

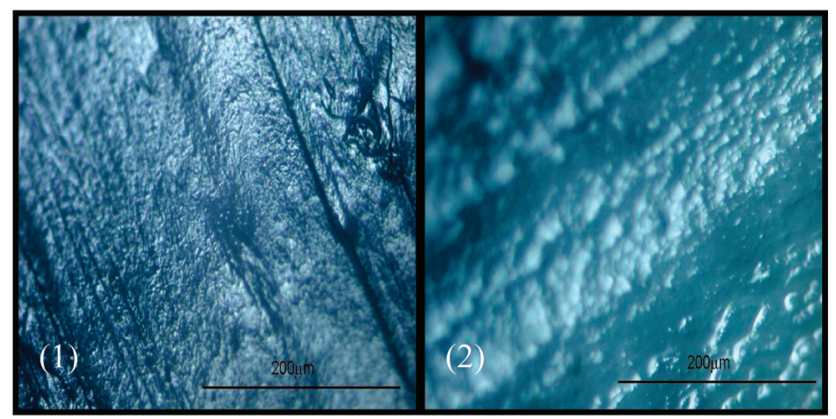

(c)

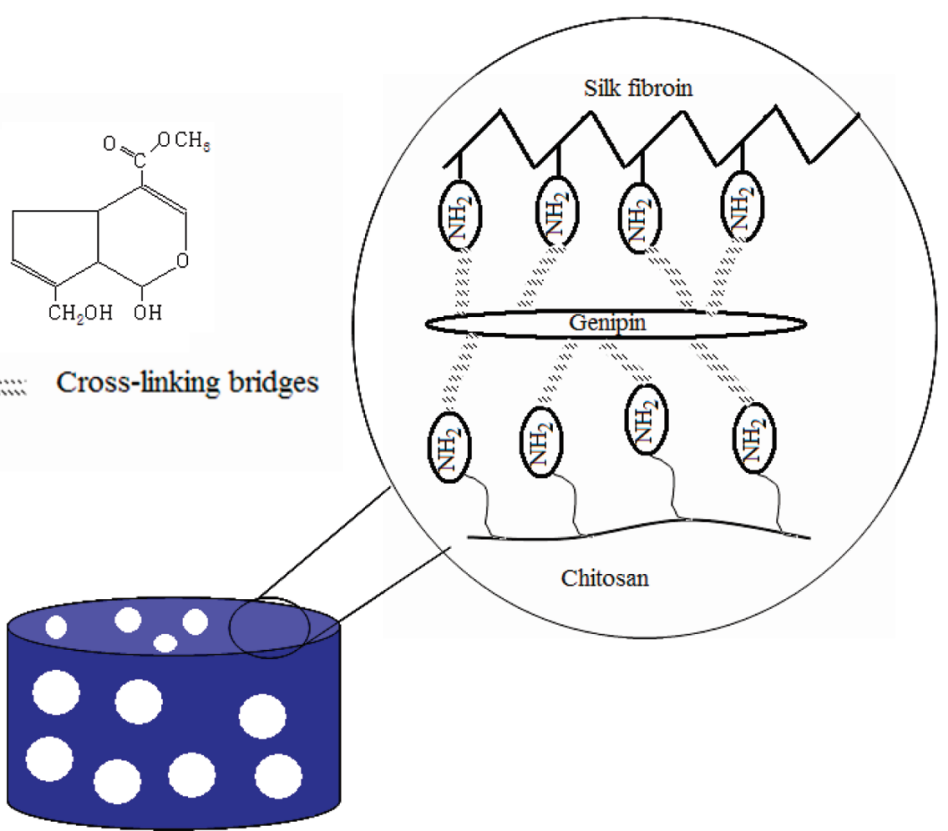

Figure 2. (a) CSG hydrogels as obtained, (b) optical micrographs of CSG hydrogels (1) CSG20G and (2) CSG80G in the wet state, and (c) schematic representation of the CSG hydrogels.

a wavelength of $570 \mathrm{~nm}$. Glycine solutions of various known concentrations were used as standards, and CS sponges that were prepared without genipin were used as control materials. After the sample was heated with ninhydrin, the number of free amino groups in the test sample was proportional to the optical absorbance of the solution. Each sample was made in triplicate. We then calculated the degree of cross-linking of the sample by following the equation ${ }^{23}$

degree of cross-linking $=$

$$
\frac{\left[(\mathrm{NH} \text { reactive amine })_{\text {fresh }}-(\mathrm{NH} \text { reactive amine })_{\text {fixed }}\right]}{(\mathrm{NH} \text { reactive amine })_{\text {fresh }} \times 100}
$$

where fresh and fixed are the mole fraction of free $\mathrm{NH}_{2}$ remaining in non-cross-linked and cross-linked samples, respectively.

A weighed amount of CSG sponge of each formulation was

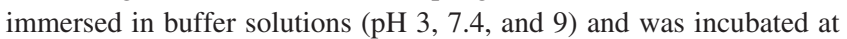
$37{ }^{\circ} \mathrm{C}$ under static conditions. The samples were left for $24 \mathrm{~h}$ in each buffer solution prior to weight determination. The swelling ratio was calculated from eq 2, where $W_{\mathrm{s}}$ is the swollen sample weight under specified environmental conditions and $W_{\mathrm{d}}$ is the dry sample weight.

$$
Q=\left[\left(W_{\mathrm{s}}-W_{\mathrm{d}}\right) / W_{\mathrm{d}}\right] \times 100
$$

To measure $W_{\mathrm{s}}$, we weighed swollen samples after the removal of excessive surface water with filter paper. We obtained dry samples by placing swollen hydrogels into a vacuum oven at $65{ }^{\circ} \mathrm{C}$ for 2 days. The samples were then weighed. Each experiment was repeated three times, and the average value was considered to be the water uptake value.

All of the viscoelastic measurements were conducted with a TRITEC2000B DMA from Triton Technology (UK) that was equipped with a compressive mode. The samples were seccionated into rectangular geometry $\left(5.4 \times 5.7 \mathrm{~mm}^{2}\right)$. Prior to the DMA experiments, the samples were equilibrated for $\sim 50 \mathrm{~min}$ in phosphate-buffered saline (PBS) solution. Three samples were used in each analysis. We analyzed all samples under wet conditions using PBS in a Teflon reservoir. The temperature was controlled by a sensor that was located in the bath. 

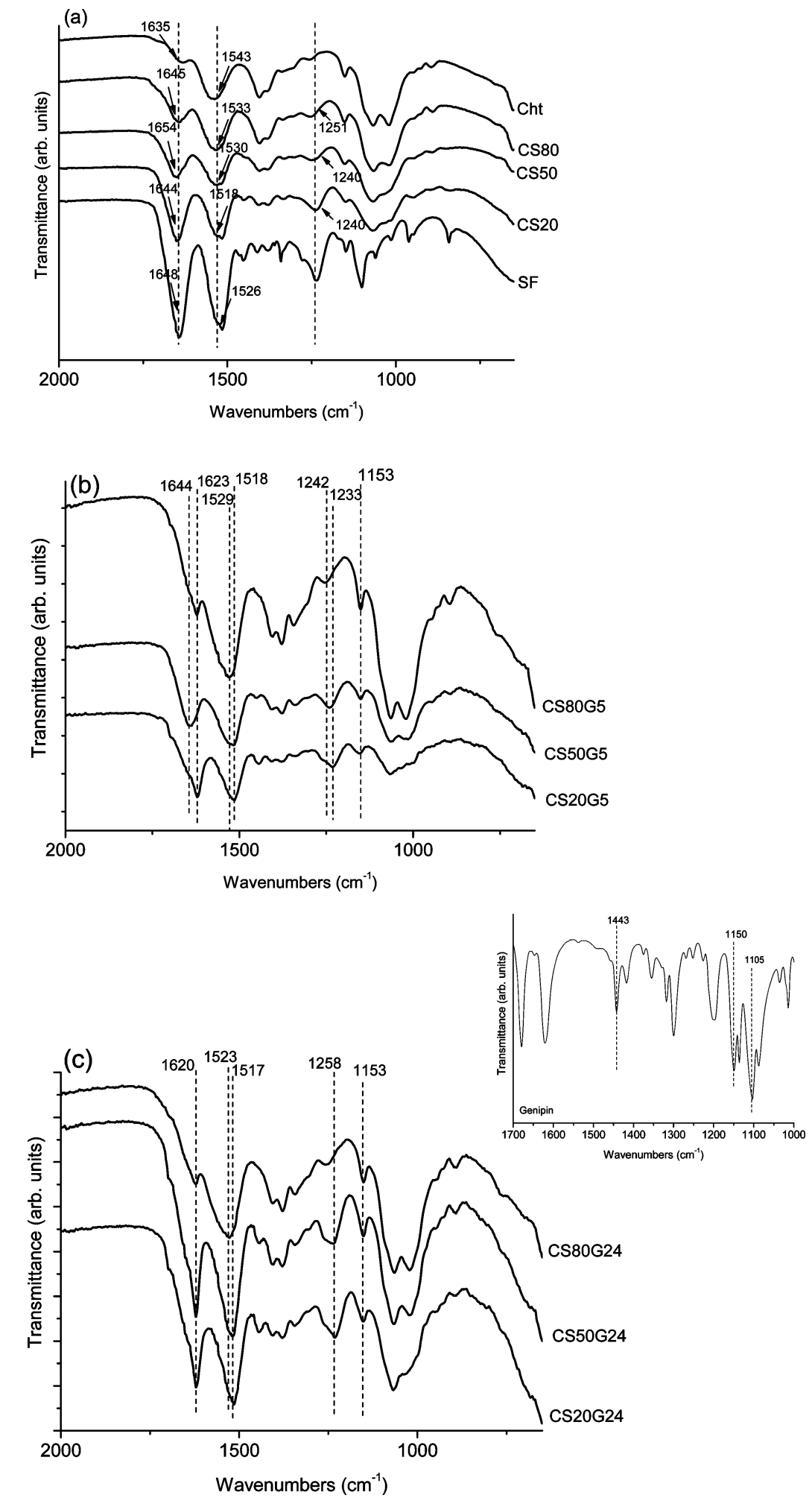

Figure 3. FTIR spectra of (a) CS blended samples and CSG sponges obtained after (b) 5 and (c) $24 \mathrm{~h}$ of reaction time.

The frequency scans $(0.1-100 \mathrm{~Hz})$ with acquisitions of 15 points per decade were performed at $37{ }^{\circ} \mathrm{C}$ with heat rate of $2{ }^{\circ} \mathrm{C} / \mathrm{min}$. The DMA results were presented in terms of two main parameters: storage modulus $\left(E^{\prime}\right)$ and loss modulus $\left(E^{\prime \prime}\right)$.

In Vitro Cell Culture Studies. Prior to cell culture studies, CS80G, CS50G, and CS20G sponges were sterilized by an immersion in 70\% ethanol solution overnight, were washed twice in sterile ultrapure water, and were air dried in a sterile environment.

To assess the eventual cytotoxicity of the developed CSG sponges, extracts of all sponges were prepared and placed in contact with a mouse fibroblast-like cell line, L929 (L929 cells; ECACC, UK), and were tested by the use of an MTS (3-(4,5-dimethylthiazol-2-yl)-5-(3carboxymethoxyphenyl)-2-(4-sulfophenyl)- $2 \mathrm{H}$-tetrazolium) assay in accordance with the protocols described in ISO/EN $10993 .{ }^{32}$ Cells were cultured in basic Dulbecco's modified Eagle's medium (DMEM, SigmaAldrich) without phenol red and were supplemented with $10 \%$ fetal bovine serum (FBS, Gibco, UK) and $1 \%$ antibiotic/antimycotic (A/B, Gibco, UK) solution. L929 cells were incubated at $37{ }^{\circ} \mathrm{C}$ in an atmosphere containing $5 \% \mathrm{CO}_{2}$ until $90 \%$ confluence was achieved. Then, a cell suspension with a concentration of $8 \times 10^{4}$ cells $\cdot \mathrm{mL}^{-1}$ 

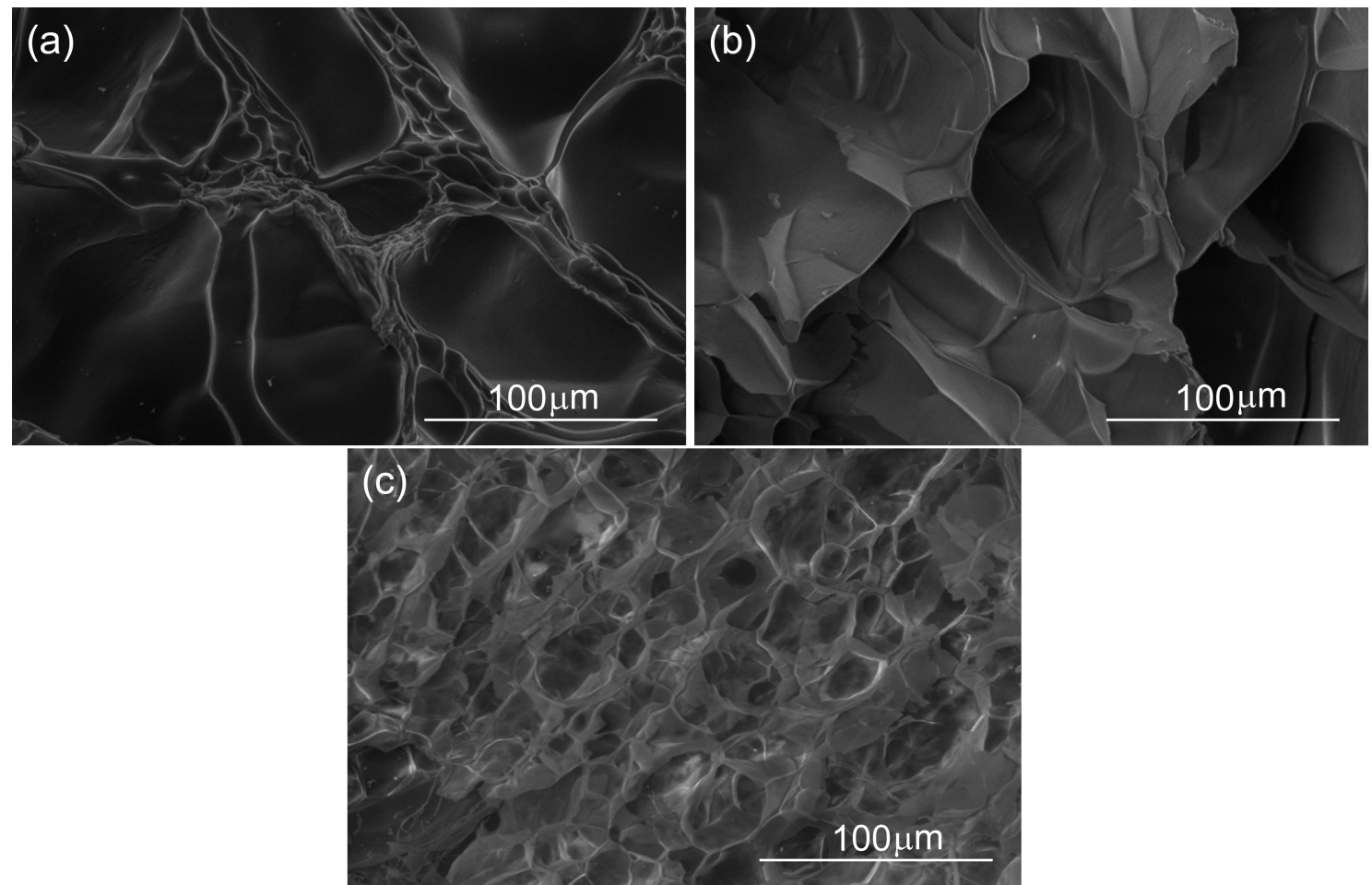

Figure 4. ESEM images of the CSG sponges (a) CS80G, (b) CS50G, (c) and CS20G.
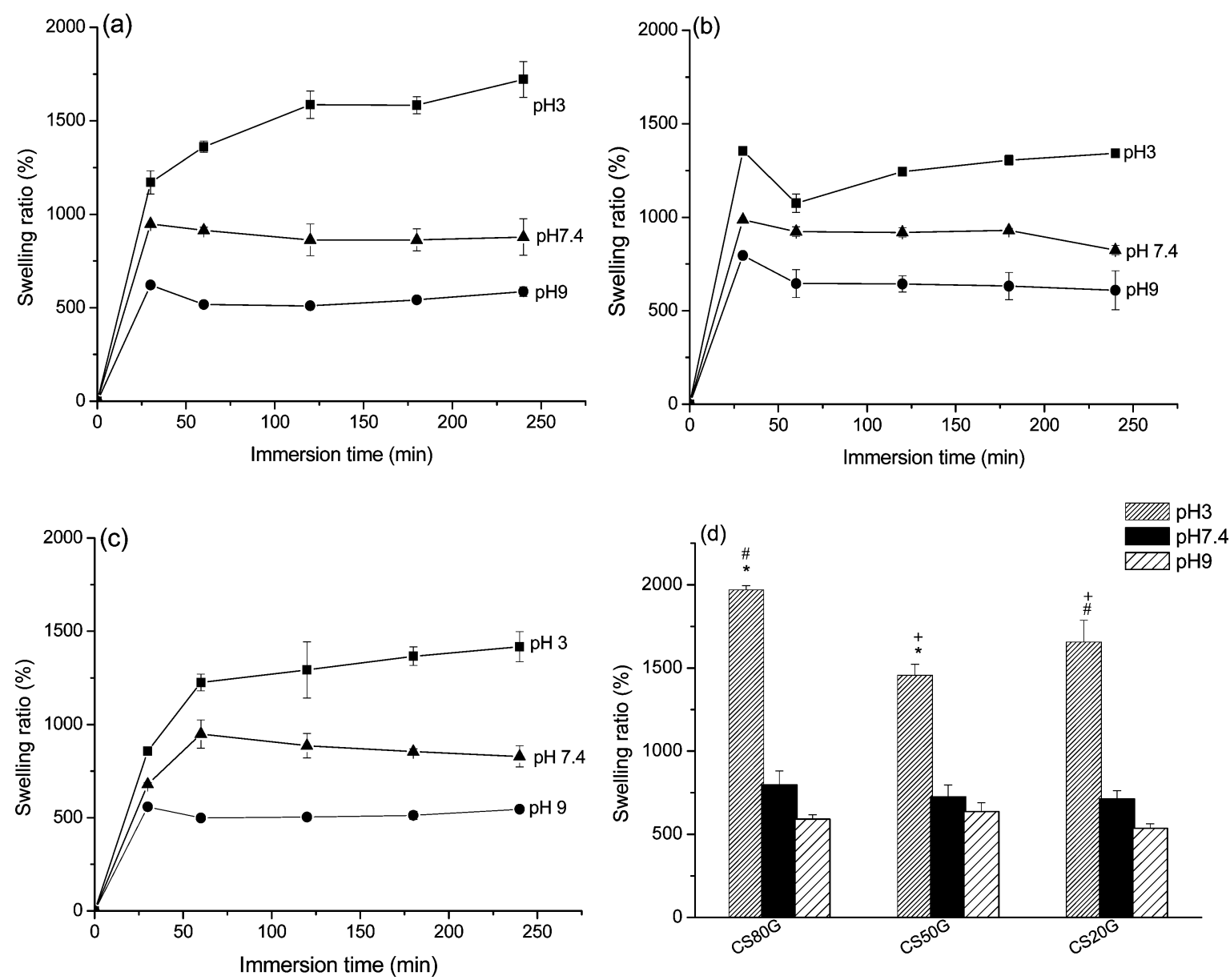

Figure 5. The $\mathrm{pH}$-dependent swelling behavior of CSG hydrogels (a) CS80G, (b) CS50G, and (c) CS20G after $4 \mathrm{~h}$ of immersion time at $37{ }^{\circ} \mathrm{C}$ in PBS and (d) the comparative swelling ratio of cross-linked samples after $24 \mathrm{~h}$ of immersion time in PBS. Data represent the mean \pm standard deviation ( $n=3 ; p<0.05$, two-way ANOVA).

were prepared as described in previous works. ${ }^{33}$ The relative viability (\%) of the L929 cells was determined for each CSG sponge's extracts 
Table 2. Values of Storage Modulus ( $E^{\prime}$, kilopascals) and Loss Modulus ( $E^{\prime \prime}$, kilopascals) for CSG Sponges

\begin{tabular}{ccc}
\hline sample & $E^{\prime}(\mathrm{kPa})^{a}$ & $E^{\prime \prime}(\mathrm{kPa})^{a}$ \\
\hline CS80G & $79.9 \pm 12.5$ & $20.3 \pm 6.6$ \\
CS50G & $32.6 \pm 0.8$ & $6.2 \pm 0.1$ \\
CS20G & $578.6 \pm 28.8$ & $109.9 \pm 11.1$ \\
\hline
\end{tabular}

${ }^{a}$ Values are means of a triplicate \pm standard deviation $(p<0.05$, twoway ANOVA).

Table 3. Results Obtained from Cytotoxicity Tests Performed Using Extracts of Chitosan and Cross-Linked CS-Based Sponges

\begin{tabular}{lcrrc}
\hline & \multicolumn{4}{c}{ cell viability $(\%)^{a}$} \\
\cline { 2 - 5 } sample & \multicolumn{1}{c}{ 1 day } & \multicolumn{1}{c}{3 days } & \multicolumn{1}{c}{7 days } & \multicolumn{1}{c}{14 days } \\
\hline CS80G & $79.1 \pm 13.3$ & $95.4 \pm 23.2$ & $110.8 \pm 5.5$ & $125.1 \pm 12.4$ \\
CS50G & $53.5 \pm 21.1$ & $101.1 \pm 16.9$ & $96.3 \pm 6.9$ & $122.0 \pm 3.4$ \\
CS20G & $69.5 \pm 29.7$ & $132.9 \pm 53.2$ & $101.8 \pm 9.5$ & $122.2 \pm 7.6$ \\
\hline
\end{tabular}

${ }^{a}$ We determined the values by taking into account the fact that TCPs (negative control) corresponded to $100 \%$. Latex was used as a positive control of cell death and produced cell viability values that were considered to be negligible $(<0.5 \%)$.

and was compared with tissue culture polystyrene (TCPS), which was used as a negative control of cell death. Latex extracts were considered to be a positive control of cellular death. After each time point, extract solutions were removed and cells were washed in a PBS (SigmaAldrich) solution. Then, we performed the MTS test to assess the cellular viability of L929 cells in contact with CSG sponge extracts. For this assay, we prepared an MTS solution by using a 1:5 ratio of MTS reagent and culture medium containing DMEM (without phenol red), $10 \% \mathrm{FBS}$, and $1 \% \mathrm{~A} / \mathrm{B}$ solution, followed by a $3 \mathrm{~h}$ incubation period at $37^{\circ} \mathrm{C}$. Finally, the optical density (OD) was read at $490 \mathrm{~nm}$ on a multiwell microplate reader (Synergy HT, Bio-Tek Instruments). We conducted all cytotoxicity screening tests by using six replicates.

We performed in vitro cell tests by using a cell suspension of ATDC5 chondrocyte-like cells (mouse 129 teratocarcinoma AT805 derived, ECACC, UK) at a concentration of $2.4 \times 10^{5}$ cells per sponge (with an approximate volume of $0.125 \mathrm{~mm}^{3}$ ). Each sample was made in triplicate. Cell-sponge constructs were incubated at $37{ }^{\circ} \mathrm{C}$ in a humidified $95 / 5 \%$ air/ $/ \mathrm{CO}_{2}$ atmosphere and were maintained for 14,21 , and 28 days by the use of a culture medium that consisted of DMEM and Ham's F12 (DMEM-F12, Gibco, UK) that was supplemented with $10 \%$ FBS (Gibco, UK), 2 mM L-glutamine (Sigma), and 1\% A/B (Gibco, UK) solution. The culture medium was replaced twice a week. After 14, 21, and 28 days of culture, the medium was removed, samples were washed with PBS solution and assessed for SEM analysis, DNA was quantified, and GAGs were detected.

The cell morphology and the proliferation of ATDC5-seeded CSG sponges were observed by SEM (Leica Cambridge S-360, UK). For this purpose, after each culturing period, ATDC5 cell-sponge constructs were fixed in a $4 \%$ formalin solution (Sigma) for $60 \mathrm{~min}$ at 4 ${ }^{\circ} \mathrm{C}$ and were dehydrated by the use of a series of ethanol solutions (25, $50,70$, and $100 \% \mathrm{v} / \mathrm{v})$. Afterward, constructs were air dried overnight at RT and were sputter coated with gold by the use of a Fisons Instruments coater (Polaron SC 502, UK) with a current set at $18 \mathrm{~mA}$ at a coating time of $120 \mathrm{~s}$ before being observed by SEM.

We determined ATDC5 cell proliferation onto CSG sponges by using a fluorimetric double-strand DNA quantification kit (PicoGreen, Molecular Probes, Invitrogen, UK). For this purpose, samples that were collected at 14, 21, and 28 days were transferred into $1.5 \mathrm{~mL}$ microtubes containing $1 \mathrm{~mL}$ of ultrapure water. ATDC5 cell-sponge constructs were incubated for $1 \mathrm{~h}$ at $37{ }^{\circ} \mathrm{C}$ in a water bath and were then stored in a $-80{ }^{\circ} \mathrm{C}$ freezer until they were tested. Prior to dsDNA quantification, constructs were thawed and sonicated for $15 \mathrm{~min}$. Samples and standards (ranging from 0 to $2 \mathrm{mg} \cdot \mathrm{mL}^{-1}$ ) were prepared and mixed with a PicoGreen solution in a 200:1 ratio and were placed on an opaque 96-well plate. Each sample or standard was made in triplicate. The plate was incubated for $10 \mathrm{~min}$ in the dark, and fluorescence was measured on a microplate ELISA reader (BioTek) with an excitation of 485/20 nm and an emission of 528/20 nm. A standard curve was created, and sample DNA values were read from the standard graph.

The GAGs quantification assay ${ }^{34}$ was used to detect chondrogenic ECM formation after 14, 21, and 28 days of culture. We obtained GAG standards by preparing a chondroitin sulfate solution that ranged from 0 to $30 \mathrm{mg} \cdot \mathrm{mL}^{-1}$. To each well of a 96 -well plate were added samples or standards in triplicate, and then the dimethylmethylene blue reagent (DMB, Sigma-Aldrich) was added, and the solution was mixed. The OD was immediately measured at $525 \mathrm{~nm}$ on a microplate ELISA reader. A standard curve was created, and GAG sample values were read from the standard graph.

Statistical Analysis. We conducted the statistical analysis of the data by two-way ANOVA with Dunnett's post test by using GraphPad Prism version 5.0 for Windows (GraphPad Software, San Diego, http:// www.graphpad.com). Differences between the groups with $p<0.05$ were considered to be statistically significant.

\section{Results and Discussion}

Chitosan/Silk Fibroin (CS) Blended Solution Characterization. Prior to the preparation of the CSG hydrogel network, the CS blended solution behaviors were examined by means of rheological measurements. Figure $1 \mathrm{a}-\mathrm{c}$ shows that both moduli of all CS blended solutions increase with time, which demonstrates the gel-like properties of the CS blended solutions. Some rheological studies ${ }^{35}$ reported that the gel-like properties of cht solutions may be associated with the wormlike character of the cht chain solution, which may favor macromolecular ordering and self association through hydrophobic interactions, which renders a weak network. Also, the acid medium induced the formation of a gel from native Bombyx mori silk, which was detected by a rise in the storage modulus. ${ }^{36}$ During genipin cross-linking, the physical chain entanglements within the CS blended system are replaced by chemical crosslinkages, which are able to form CSG hydrogels. The build-up hydrogel network formation was also monitored by the behavior of the $G^{\prime}, G^{\prime \prime}, \eta^{\prime}$, and $\tan \delta$ versus time curves up to $3 \mathrm{~h}$. Prior to gelation, the loss modulus $G^{\prime \prime}$ is greater than elastic modulus $G^{\prime}$, which indicates a liquidlike behavior in the beginning of the reaction. When chemical cross-linkages are introduced, the physical chain entanglements of the polymeric chains are gradually replaced by a permanent covalent network that favors the increase in $G^{\prime}$ over time, which is observed in Figure 1d-f. With the progress of reaction, the increasing rate of $G^{\prime}$ was higher than that of $G^{\prime \prime}$, which lead to a $G^{\prime} / G^{\prime \prime}$ crossover that is described as the gelation time or gel point, ${ }^{37}$ where the transition from the liquidlike to the solidlike behavior takes place. From time sweep results (Figure $1 \mathrm{~d}-\mathrm{f}$ ), the measured values of the gelation time were 12, 39, and $20 \mathrm{~min}$ for CS80G, CS50G, and CS20G, respectively. The speed of the reactions may be associated with different interactions of genipin with the blend components. Previous studies ${ }^{22}$ that involved gelatin and cht indicated that genipin could efficiently cross-link cht much faster than it could gelatin. As expected, the viscosity and both moduli increase for all CSG solutions (Figure 1d-f) when compared with CS blended solutions (Figure 1a-c). The statistical analysis of the data evidenced significant differences $(p<0.05)$ in the $\tan \delta$ values, which decrease more gradually with time (less than 0.3 upon gelation, Figure 1d-f) for CSG solutions because the magnitude of the rise in $G^{\prime}$ is higher than that of $G^{\prime \prime}$ as a result of the formation of the hydrogels. It is worth mentioning that the inflection of the rheological curves of CS50G (Figure 1e) and CS20G (Figure 1f) in both moduli at $80 \mathrm{~min}$ (CS20G) and $108 \mathrm{~min}$ (CS50G) suggests that the SF fraction reacts more slowly with genipin. 
0 day

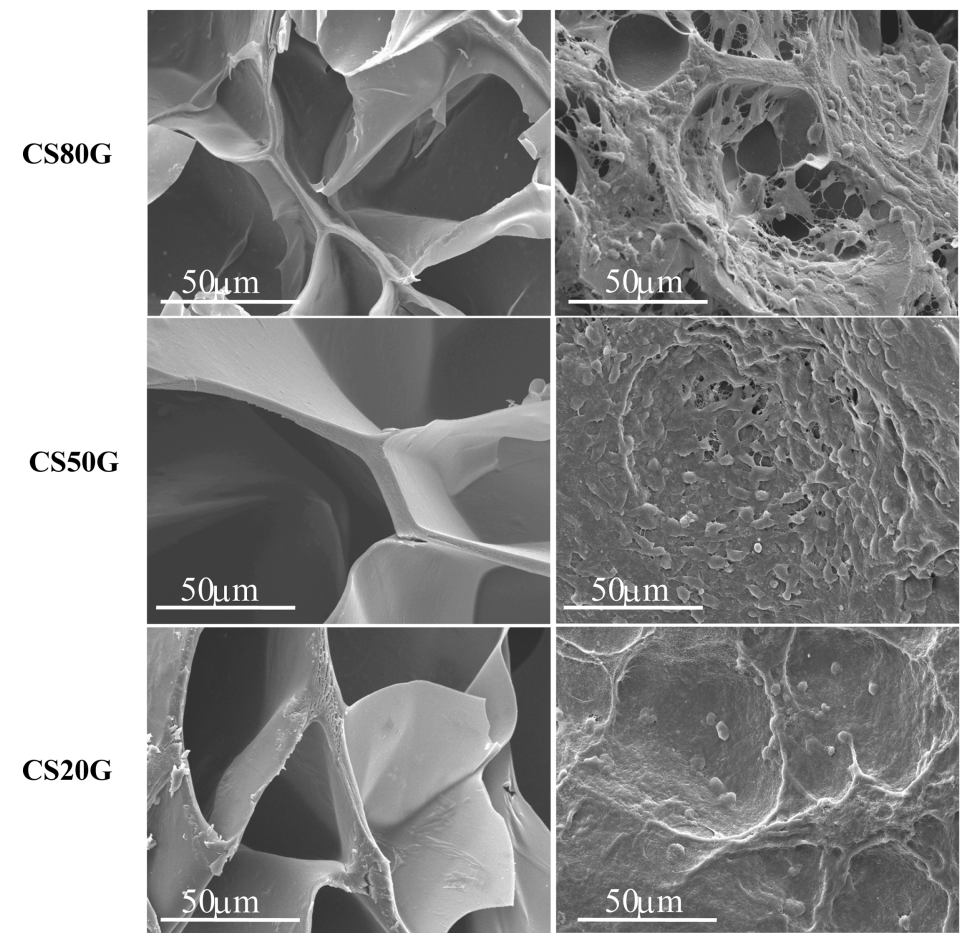

21 days

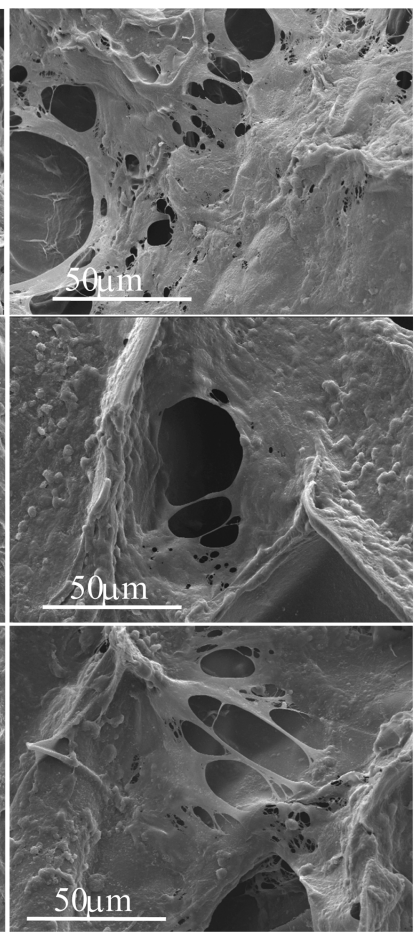

28 days

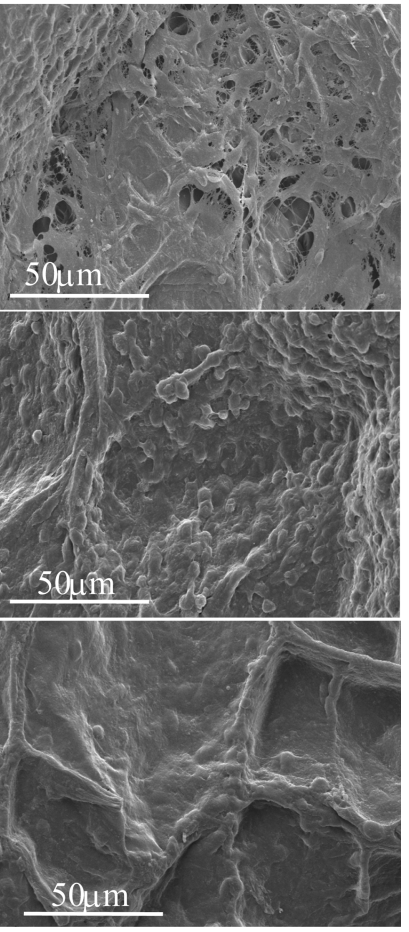

Figure 6. SEM micrographs of ATDC5 cells cultured on the surface of CS80G, CS50G, and CS20G after 0, 14, 21, and 28 days.

CS80G

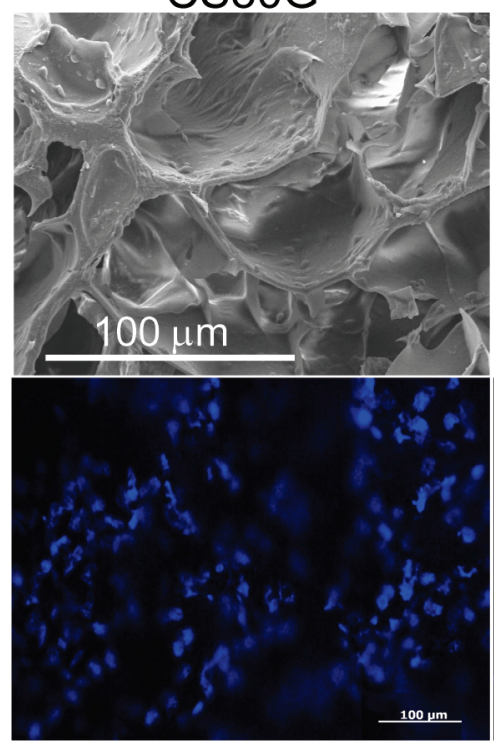

CS50G

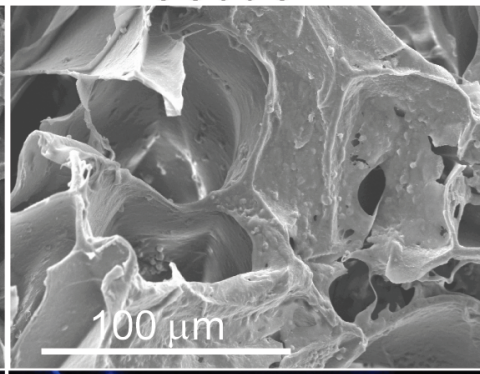

CS20G

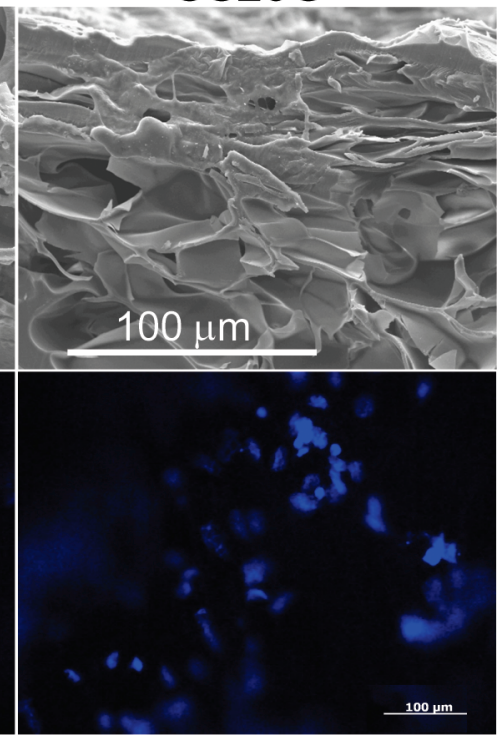

Figure 7. SEM micrographs (top) and DAPI fluorescence staining (bottom) of cross sections of the sponges seeded with ATDC5 cells for 28 days.

Cross-Linking Reactions and Formation of CSG Hydrogels. The formation of strong intermolecular associations through chemical cross-linking (covalent bond forming) on blended systems may promote the homogenization of these systems to produce stable and ordered materials. Considering that compounds containing amino groups with genipin is a moderate reaction, ${ }^{37}$ we conducted all reactions for $24 \mathrm{~h}$ at 37 ${ }^{\circ} \mathrm{C}$. Table 1 summarizes the details of the cross-linking reactions as a function of time. We observed that the light-yellow solutions gradually turned into a dark-blue gels. In all hydrogels, the blue coloration was deepest near the surface that was exposed to air, and it gradually moved further into the sample with the increase in the cross-linking reaction time. The dark-blue coloration that appeared in the hydrogels is associated with the oxygen-radical-induced polymerization of genipin as well as its reaction with amino groups/amino acids. ${ }^{21,38}$ The speed of the reactions was found to be dependent on the CS ratio, which is evidenced by the rheological data. For example, the CS80G formulation has a higher cht content and forms a dark-blue gel within $3 \mathrm{~h}$ (Table 1), whereas the other reactions take a longer time to form a consistent dark-blue gel. Fully gelled dark-blue hydrogels with symmetrical structures were formed after $24 \mathrm{~h}$ at $37{ }^{\circ} \mathrm{C}$ (Figure 2a, Table 1). Previous studies ${ }^{39}$ have demonstrated that an increase in the efficacy of the genipin reaction can be reached by increasing the temperature and decreasing the $\mathrm{pH}$. Chen et al. ${ }^{21}$ reported that the speed of the 


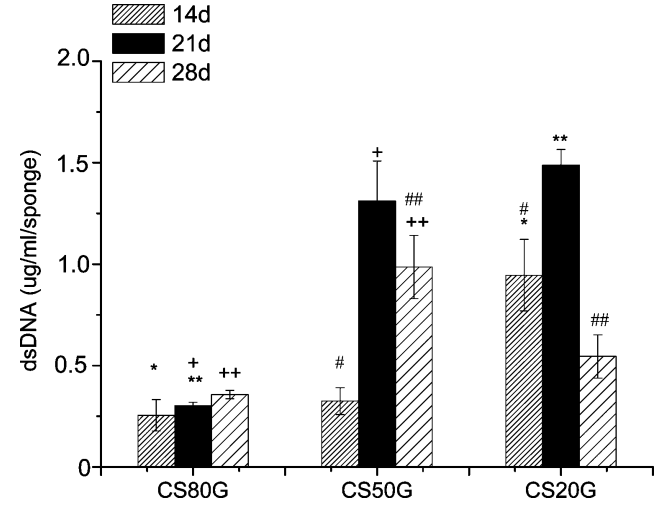

Figure 8. DNA content of ATDC5 cells on CSG sponges as a function of time $(p<0.05$, two-way ANOVA).

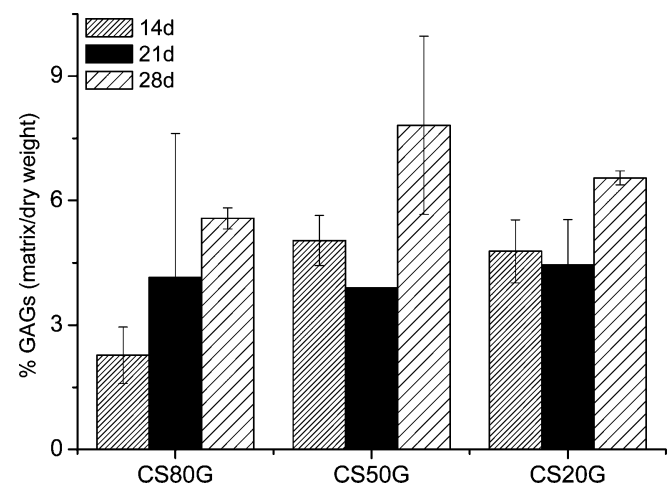

Figure 9. GAGs quantification assay of ATDC5 cells cultured on CSG sponges.

reaction of cht with genipin at $37^{\circ} \mathrm{C}$ was faster than that at lower temperatures because of the higher level of molecular mobility at this temperature. Motta et al. ${ }^{25}$ observed that genipin cross-linked SF films were formed after $5 \mathrm{~h}$ of reaction at 65 ${ }^{\circ} \mathrm{C}$, followed by the casting of the solutions at RT.

Representative optical micrographs of hydrogels are presented in Figure $2 \mathrm{~b}$ and suggest that their surfaces were dark blue, homogeneous, and globular. Although the mechanism of the interaction of genipin with SF is currently unknown, the reaction mechanism can be similar to that observed for amino-groupcontaining compounds. ${ }^{21,40}$ In the reaction mechanism that is described in these studies, the ester groups of genipin interact with the amino groups of cht and proteins, which leads to the formation of secondary amide linkages. Additionally, the amino groups initiate nucleophilic attacks of genipin, which results in the opening of the dihydropyran ring, followed by a number of reaction steps. Some authors ${ }^{38}$ reported that genipin preferentially reacts with the amino acids lysine and arginine of certain proteins. In our studies, the fibroin chain contains a very low percentage of these amino acids ( $0.6 \%$ for both), mainly in the hydrophilic blocks. For this reason, the cross-linking sites are low in number and the kinetics should be reasonably slow for the SF fraction. However, cht has a high percentage of amine groups that can be directly cross-linked with genipin. ${ }^{41}$ Therefore, the association of SF with cht favored genipin crosslinking, and as result, stable and ordered hydrogels were formed. Moreover, because the cross-linking reactions of CSG solutions took place under acidic conditions ( $\mathrm{pH}$ of approximately 4.4), the intermediate compounds could further associate to form cross-linked polymeric networks with short chains of crosslinking bridges, as reported in other studies. ${ }^{37}$ After production, the CSG hydrogels were freeze dried. A schematic representation of the resulting CSG sponges is shown in Figure 2c. The cross-linking-degree values of CSG sponges were determined by the use of the ninhydrin assay. ${ }^{31}$ The obtained values were $45.2 \pm 0.1,29.3 \pm 1.7$, and $23.9 \pm 3.1 \%$ for CS80G, CS50G, and CS20G, respectively.

FTIR Results. When CS blended systems are submitted to cross-linking with genipin, conformational changes may occur as a result of structural rearrangement of chains to form covalent bonds. To evaluate the effect of genipin on the conformation of the developed materials, we acquired FTIR spectra of noncross-linked CS samples. (See Figure 3.) The main characteristic absorption bands of cht appear at 1637, 1541, and 1150-1040 $\mathrm{cm}^{-1}$, which correspond to amide I $(\mathrm{C}=\mathrm{O})$, amide II $\left(\mathrm{NH}_{2}\right)$, and glycosidic linkage, respectively. ${ }^{43}$ Silk protein exists in three conformations, namely, random coil, silk I ( $\alpha$ form), and silk II $\left(\beta\right.$ sheet) ${ }^{44}$ The SF spectrum shows bands at 1644 and 1531 $\mathrm{cm}^{-1}$, which are assigned, respectively, to amide I and amide II bands of a random coil or silk I conformation. ${ }^{44}$ As expected, the characteristic absorptions bands of both SF and cht appear in proportion to the CS ratio. The CS spectra (Figure 3a) showed absorption bands in the range of 1654-1644 (amide I), 1543-1518 (amide II), and 1249-1235 $\mathrm{cm}^{-1}$ (amide III), and the bands at $1653-1647$ and $1250-1240 \mathrm{~cm}^{-1}$ were assigned to the $\alpha$-helix/random-coil conformation, ${ }^{45}$ whereas the $1532-1514$ $\mathrm{cm}^{-1}$ band was assigned to the $\beta$-sheet conformation. ${ }^{45}$ Even though new peaks did not appear after the reaction, the structural changes, which were caused by genipin cross-linking, can be revealed by an analysis of amides $\mathrm{I}(\mathrm{C}=\mathrm{O}$, stretching), II $(\mathrm{N}-\mathrm{H}$ deformation), and III ( $\mathrm{C}-\mathrm{N}$ stretching and $\mathrm{N}-\mathrm{H}$ deformation) in the spectra (Figure 3b,c). In the comparison of both spectra (Figure 3a,b), the amide I $\left(1644-1620 \mathrm{~cm}^{-1}\right.$ ) and amide II (1529-1517 $\mathrm{cm}^{-1}$ ) bands shift to lower wave numbers in the samples that were obtained with different reaction times. The results suggest that CSG hydrogels that were produced after $5 \mathrm{~h}$ of reaction had a heterogeneous structure that mainly consisted of $\beta$ sheets with small contributions from the $\alpha$-helix/ random-coil conformation. ${ }^{45} \mathrm{~A}$ more prolonged reaction time ( $24 \mathrm{~h})$ seems to lead to the formation of a stable $\beta$-sheet structure (silk II structure) for all CSG matrices, which was associated with the characteristic absorption bands at 1621 (amide I), 1517 (amide II), and $1254 \mathrm{~cm}^{-1}$ (Figure 3c). ${ }^{44,45}$ Collectively, these structural aspects evidenced that the genipin cross-linking of the CS blended systems was followed by protein conformational changes, which promoted the formation of CSG matrices with stable and ordered structures.

Morphological Characterization. In TE applications, it is important that the scaffold maintains its porous structure under physiological immersion conditions that are similar to those found in vitro and in vivo. Therefore, especially for systems that have the ability to uptake water such as the ones studied in this work (see next sections), the observation of the porous architecture is preferably performed under wet conditions. In this work, the morphologies of the developed sponges were investigated by ESEM. ESEM micrographs of the surfaces of CSG sponges showed very distinct surface morphologies (Figure 4) with pore sizes ranging from 29 to $167 \mu \mathrm{m}$, depending on the composition, and a decreasing tendency was found for the pore size of sponges with increasing SF content. These different morphological features may influence the biological behavior of the sponges because the hydrophilic nature of the sponges (which will be discussed in the next section) enables the complete and rapid wetting of the entire matrix by the culture medium, which allows the cells to be entrapped by the pore structure. Additionally, the micro-CT analysis enabled us to estimate the mean porosity of the CSG sponges. The obtained 
values were $81.2 \pm 1.5,83.3 \pm 2.4$, and $80.3 \pm 0.21 \%$ for CS80G, CS50G, and CS20G, respectively. Even though the mean porosity values of the sponges were not significantly different regardless of the composition of the sponges, the hydrophilicity of the sponges combined with their $80 \%$ mean porosity can promote uniform cell distribution in the entire sponge volume.

Swelling Behavior. An important aspect of the ECM is its ability to store water, which supports various cellular activities and functions. ${ }^{46}$ To study the water uptake ability of the materials and its response to the external $\mathrm{pH}$ conditions, we

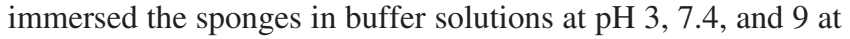
$37{ }^{\circ} \mathrm{C}$ for a predetermined time. The swelling degree of the CSG sponges was highest in the acidic solution $(\mathrm{pH} \mathrm{3)}$ ) and became lower in neutral $(\mathrm{pH} 7.4)$ and alkaline $(\mathrm{pH} 9)$ media (Figure $5 \mathrm{a}-\mathrm{d}$ ). The statistical analysis of the data evidenced significant differences $(p<0.05)$ in the swelling values at $\mathrm{pH}$ 3 mainly in the sponges that were prepared with a higher amount of cht (CS80G and CS50G). At a low pH, CSG sponges presented higher swelling degrees that were essentially due to the protonation of the free amino groups of cht. The protonation promotes the solubility of the polymeric segments and leads to polymer chain repulsion, and the interaction with water molecules allow the uptake of more water into the gel network. However, with increasing $\mathrm{pH}$, the CSG sponges exhibit a lower swelling degree after $24 \mathrm{~h}$ (Figure $5 \mathrm{~d}$ ), which is probably due to the influence of unprotonated amine groups and to crosslinks that restrict the swelling of the sponges. Generally, the swelling degree of sponges, often with a $\mathrm{pH}$ stimuli-responsive character, can be controlled by the adjustment of its composition as well as of the cross-linking extent of the material. In CSG sponges, the introduced cross-links created stable structures that avoided the dissolution of the hydrophilic polymer chains/ segments into the aqueous phase. Collectively, the swelling results demonstrated that the developed CSG sponges exhibited a $\mathrm{pH}$-dependent pattern in the range of $\mathrm{pH}$ that was studied.

Mechanical Properties. To examine the mechanical properties of the CSG sponges, we conducted compression tests under wet conditions. DMA is a suitable technique that enables us to investigate the solid-state rheological properties of materials and biomaterials as a function of temperature and frequency. ${ }^{47,48}$ In this work, the samples were kept in solution up to equilibrium and were tested in that state. Because the viscoelastic properties of the sponges were kept stable within the investigated frequency range $(0.1-100 \mathrm{~Hz})$, only the values of moduli at $1 \mathrm{~Hz}$ were chosen for comparison, and the results are summarized in Table 2. In most of the materials, $E^{\prime}$ was higher than $E^{\prime \prime}$, which indicates a solidlike behavior that is consistent with the previous rheological tests. The statistical analysis of the data evidenced significant differences $(p<0.05)$ between both moduli values. Higher moduli values were found in the sponges that were prepared with a higher amount of SF (CS20G), which suggests that the incorporation of SF to cht associated with genipin crosslinking allows the production of stiffer sponges. The FTIR results suggest that genipin cross-linking promoted the formation of $\beta$ sheets in CSG sponges. The increased regions of $\beta$ sheets imply an increase in the amount of crystalline organized domains, an increase in stiffness, and consequently, and increase in the moduli of the material.

Biological Studies. Cytotoxicity Assays. The cytotoxicity assessment of sponge extracts was carried out as a preliminary approach to assess the biocompatibility of CSG sponges. Table 3 shows the cell viability results that were obtained from the MTS test that was performed by the use of extracts of the materials under study. Results indicate that L929 cells are viable in the presence of cross-linked CS sponges' extracts. In fact, the cell viability was $\sim 100 \%$ in all sponges when compared with TCPS. This demonstrates the extremely low cytotoxicity levels of the CSG sponges.

Direct Contact Assay. Cell Adhesion and Proliferation on Sponges. SEM micrographs that were obtained from samples that resulted from culturing ATDC5 chondrocyte-like cells on CSG sponges for 14, 21, and 28 days are described in Figure 6 , and a high cellular density on the surface of the CSG sponges was observed. Additionally, cells were able to proliferate and maintain their chondrocyte morphology in all CSG sponges. The interconnectivity of the sponges was analyzed by SEM images using cross sections of ATDC5 cells that were cultured on the sponges after 28 days (Figure 7). The cellular access into inner sections of the sponge was more evident in CS80G and CS50G formulations and is likely due to a good connection among pores. DAPI pictures of cross sections of the sponges (Figure 7) revealed the presence of cells inside all sponge formulations. These findings suggest that the cells have access to the inner section of sponges, which is indirectly promoted by a good pore interconnectivity of the studied samples.

The results that were obtained from the DNA biochemical analysis showed that the proliferation of ATDC5 chondrocytelike cells seeded onto CSG sponges tends to increase with the culturing time (Figure 8). According to the two-way ANOVA statistical analysis of the data, significant differences $(p<0.05)$ were found in the DNA values (Figure 8). After 14 days, cell proliferation significantly increased in CS20G compared with other formulations (CS80G and CS20G). However, cells that were seeded onto CS50G tended to grow better than cells that were seeded onto CS20G when the cell culture time increased. This fact can be explained by both structural differences and the pore interconnectivity of sponges, which is in agreement with previous SEM data of sponge cross-sections (Figure 7).

The synthesis of GAGs in ECM is an important function of chondrocytes and plays a significant role in regulating the chondrocyte phenotype ${ }^{49}$ and determining the cartilage natural structure. Figure 9 shows that the GAG content tends to increase with the culturing time, especially after 28 days for the different sponge compositions. Although statistical differences were not found, the results seem to indicate a tendency to increase the amount of matrix that is produced in the CS50G formulation after 28 days.

These findings indicated that the incorporation of the SF component into Cht as well as genipin cross-linking promoted an improvement of the properties of the resulting CSG sponges in terms of the adhesion and proliferation of the ATDC5 chondrocyte-like cells. Although we expected an increase in the amount of silk to enhance the cell studied parameters because of its excellent biocompatibility, ${ }^{14,15}$ the performed biological studies suggested that the cells that were seeded onto CS50G sponges presented better cellular responses compared with other formulations (CS80G and CS20G).

\section{Conclusions}

Novel biodegradable cross-linked CSG blended-based hydrogels were successfully prepared. The resultant CSG sponges were fully gelled, dark-blue symmetric structures that showed interesting characteristics: (i) stable and ordered structures that were presumably due to protein conformational changes from $\alpha$-helix/random-coil to $\beta$-sheet structures, (ii) different pore sizes and distinct morphologies, which are related to the CS ratio, 
(iii) $\mathrm{pH} /$ swelling dependence at $\mathrm{pH} 3,7.4$, and 9, and (iv) stiffer hydrogels. In accordance with the tests performed in this work, the blending of SF and cht and, subsequently, genipin crosslinking promoted the formation of stable structures that favored adhesion, proliferation, and matrix production of chondrocytelike cells. The variation in the pore size of the CSG sponges did not appear to affect the cellular adhesion. Seeded cells showed high adhesion and proliferation as well as matrix production, especially in the CS50G formulation. The positive cellular response together with the sponges' intrinsic properties suggest that cross-linked CS-based sponges may be good candidates for cartilage TE scaffolding.

Acknowledgment. S.S.S. and M.T.R. thank the Portuguese Foundation for Science and Technology (FCT) for Ph.D. scholarships (SFRH/BD/8658/2002 and SFRH/BD/30745/2006, respectively). A.F.M.P. thanks the FCT and FEDER for a grant (POCI/FIS/61621/2004). This work was partially supported by the European-Union-funded STREP project HIPPOCRATES (NMP3-CT-2003-505758) and was carried out under the scope of the European NoE EXPERTISSUES (NMP3-CT-2004500283). We also acknowledge Adriano Pedro for his contribution to the micro-CT analysis.

\section{References and Notes}

(1) Vinatier, C.; Guicheux, J.; Daculsi, G.; Layrolle, P.; Weiss, P. BioMed. Mater. Eng. 2006, 16, S107-S113.

(2) Junqueira, L. C.; Carneiro, J. Basic Histology: Text \& Atlas; McGrawHill: New York, 2005; p 128.

(3) Mano, J. F.; Reis, R. L. J. Tissue Eng. Regener. Med. 2007, 1, 261273.

(4) Chung, C.; Burdick, J. A. Adv. Drug Delivery Rev. 2008, 60, 243262.

(5) Yan, J. H.; Qi, N. M.; Zhang, Q. Q. Artif. Cells, Blood Substitutes, Biotechnol. 2007, 35, 333-344.

(6) Stoltz, J. F.; Bensoussan, D.; Decot, V.; Netter, P.; Ciree, A.; Gillet, P. Bio-Med. Mater. Eng. 2006, 16, S3-S18.

(7) De Franceschi, L.; Grigolo, B.; Roseti, L.; Facchini, A.; Fini, M.; Giavaresi, G.; Tschon, M.; Giardino, R. J. Biomed. Mater. Res., Part A., 2005, 74, 612-622.

(8) Suh, J. K. F.; Matthew, H. W. T. Biomaterials 2000, 21, 2589-2598.

(9) Chen, G.; Ushida, T.; Tateishi, T. Mater. Sci. Eng., C 2001, 17, 6369.

(10) Liao, E.; Yaszemski, M.; Krebsbach, P.; Hollister, S. Tissue Eng. 2007, $13,537-550$

(11) Aigner, T.; Stove, J. Adv. Drug Delivery Rev. 2003, 55, 1569-1593.

(12) Kumar, M. N. V. R.; Muzzarelli, R. A. A.; Muzzarelli, C.; Sashiwa, H.; Domb, A. J. Chem. Rev., 2004, 104, 6017-6084.

(13) Oliveira, J. T.; Crawford, A.; Mundy, J. M.; Moreira, A. R.; Gomes, M. E.; Hatton, P. V.; Reis, R. L. J. Mater. Sci.: Mater. Med. 2007, $18,295-302$.

(14) Vepari, C.; Kaplan, D. L. Prog. Polym. Sci. 2007, 32, 991-1007.

(15) Altman, G. H.; Diaz, F.; Jakuba, C.; Calabro, T.; Horan, R. L.; Chen, J.; Lu, H.; Richmond, J.; Kaplan, D. L. Biomaterials 2003, 24, 401416.

(16) Santin, M.; Motta, A.; Freddi, G.; Cannas, M. J. Biomed. Mater. Res. 1999, 46, 382-389.

(17) Unger, R. E.; Sartoris, A.; Peters, K.; Motta, A.; Migliaresi, C.; Kunkel, M.; Bulnheim, U.; Rychly, J.; Kirkpatrick, C. J. Biomaterials 2007, 28, 3895-3976.
(18) Li, Z.; Zhang, M. J. Biomed. Mater. Res., Part A 2005, 75, 485-493.

(19) Hsu, S. H.; Whu, S. W.; Hsieh, S. C.; Tsai, C. L.; Chen, D. C.; Tan, H. S. Artif. Organs 2004, 28, 693-703.

(20) Koo, H. J.; Song, Y. S.; Kim, H. J.; Lee, Y. H.; Hong, S. M.; Kim, S. J.; Kim, B. C.; Jin, C.; Lim, C. J.; Park, E. H. Eur. J. Pharmacol. 2004, 495, 201-208.

(21) Chen, H. M.; Wei, O. Y.; Bisi, L. Y.; Martoni, C.; Prakash, S. J. Biomed. Mater. Res., Part A 2005, 75, 917-927.

(22) Mi, F. L. Biomacromolecules 2005, 6, 975-987.

(23) Yuan, Y.; Chesnut, B. M.; Utturkar, G.; Haggard, W. O.; Yang, Y.; Ong, J. L.; Bumgardner, J. D. Carbohydr. Polym. 2007, 68, 561-567.

(24) Chang, W. H.; Chang, Y.; Lai, P. H.; Sung, H. W. J. Biomater. Sci., Polym. Ed. 2003, 14, 481-495.

(25) Motta, A.; Barbato, B.; Torricelli, P.; Migliaresi, C. J. Bioact. Compat. Polym., submitted 2007.

(26) Silva, S. S.; Maniglio, D.; Motta, A.; Mano, J. F.; Reis, R. L.; Migliaresi, C. Macromol. Biosci. 2008, 8, 766-774.

(27) Atsumi, T.; Miwa, Y.; Kimata, K.; Ikawa, Y. Cell Differ. Dev. 1990, 30, 109-116.

(28) Hirai, A.; Odani, H.; Nakajima, A. Polym. Bull. 1991, 26, 87-94.

(29) Signini, R.; Filho, S. P. C. Polym. Bull. 1999, 42, 159-166.

(30) Macosko, C. W. Rheology: Principles, Measurements, and Applications; VCH: New York, 1994.

(31) Friedman, M. J. Agric. Food Chem. 2004, 52, 385-406.

(32) ISO/10993. Test on Extracts. In Biological Evaluation of Medical Devices. Part 5: Tests for Cytotoxicity: In Vitro Methods; International Organization for Standardization: Geneva, Switzerland, 1992.

(33) Gomes, M. E.; Reis, R. L.; Cunha, A. M.; Blitterswijk, C. A.; Bruijn, J. D. Biomaterials 2001, 22, 1911-1917.

(34) Biopolymer Methods in Tissue Engineering; Hollander, A. P., Hatton, P. V., Eds.; Human Press: New York, 2004.

(35) Monal, W. A.; Goycoolea, F. M.; Peniche, C.; Ciapara, H. Polym. Gels Networks 1998, 6, 429-440.

(36) Terry, A. E.; Knight, D. P.; Porter, D.; Vollrath, F. Biomacromolecules 2004, 5, 768-772.

(37) Tang, Y. F.; Du, Y. M.; Hu, X. W.; Shi, X. W.; Kennedy, J. F. Carbohydr. Polym. 2007, 67, 491-499.

(38) Mi, F. L.; Sung, H. W.; Shyu, S. S. J. Polym. Sci., Part A: Polym. Chem. 2000, 38, 2804-2814.

(39) Sung, H. W.; Huang, R. N.; Huang, L. L. H.; Tsai, C. C.; Chiu, C. T. J. Biomed. Mater. Res. 1998, 42, 560-567.

(40) Sung, H. W.; Chang, Y.; Liang, I. L.; Chang, W. H.; Chen, Y. C. J. Biomed. Mater. Res. 2000, 52, 77-87.

(41) Butler, M. F.; Ng, Y. F.; Pudney, P. D. A. J. Polym. Sci., Part A: Polym. Chem. 2003, 41, 3941-3953.

(42) Mi, F. L.; Sung, H. W.; Shyu, S. S. J. Appl. Polym. Sci. 2001, 81, 1700-1711.

(43) Pawlak, A.; Mucha, A. Thermochim. Acta 2003, 396, 153-166.

(44) Um, I. C.; Kweon, H. Y.; Park, Y. H.; Hudson, S Int. J. Biol. Macromol. 2001, 29, 91-97.

(45) Wilson, D.; Valluzi, R.; Kaplan, D Biophys. J. 2000, 78, 2690-2701.

(46) Cooper, G. M. The Cell: A Molecular Approach, 2nd ed.; Sinauer Associates: Sunderland, MA, 2000.

(47) Menard, K. P. Dynamic Mechanical Analysis: A Practical Introduction; CRC Press: Boca Raton, FL, 1999.

(48) Mano, J. F.; Reis, R. L.; Cunha, A. M. Dynamic Mechanical Analysis in Polymers for Medical Applications. In Polymer Based Systems on Tissue Engineering, Replacement, and Regeneration; Reis, R. L., Cohn, D., Eds.; Kluwer Academic: Dordrecht, The Netherlands, 2002; p 139.

(49) Lee, C.-T.; Huang, C.-P.; Lee, Y.-D. Biomacromolecules 2006, 7, 2200-2209.

BM800874Q 